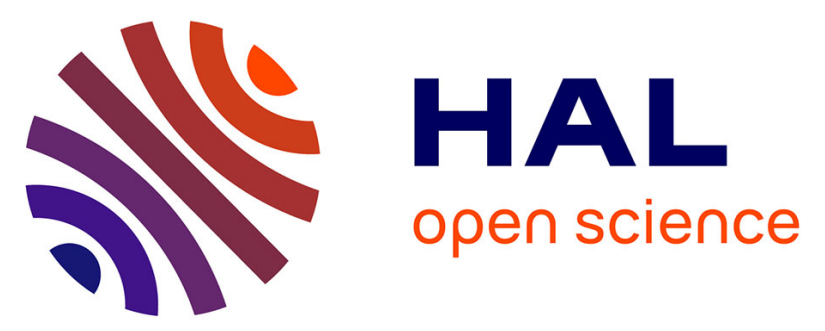

\title{
Enhanced electrocatalytic activity and selectivity of glycerol oxidation triggered by nanoalloyed silver-gold nanocages directly grown on gas diffusion electrodes
}

Rihab Boukil, Nazym Tuleushova, Didier Cot, Bertrand Rebière, Valerie

Bonniol, Julien Cambedouzou, Sophie Tingry, David Cornu, Yaovi Holade

\section{To cite this version:}

Rihab Boukil, Nazym Tuleushova, Didier Cot, Bertrand Rebière, Valerie Bonniol, et al.. Enhanced electrocatalytic activity and selectivity of glycerol oxidation triggered by nanoalloyed silver-gold nanocages directly grown on gas diffusion electrodes. Journal of Materials Chemistry A, 2020, 8 (18), pp.8848-8856. 10.1039/d0ta01063d . hal-02873007

\section{HAL Id: hal-02873007 \\ https://hal.umontpellier.fr/hal-02873007}

Submitted on 23 Nov 2020

HAL is a multi-disciplinary open access archive for the deposit and dissemination of scientific research documents, whether they are published or not. The documents may come from teaching and research institutions in France or abroad, or from public or private research centers.
L'archive ouverte pluridisciplinaire HAL, est destinée au dépôt et à la diffusion de documents scientifiques de niveau recherche, publiés ou non, émanant des établissements d'enseignement et de recherche français ou étrangers, des laboratoires publics ou privés. 
Enhanced electrocatalytic activity and selectivity of glycerol oxidation triggered by nanoalloyed silver-gold nanocages directly grown onto gas diffusion electrodes

Rihab Boukil,${ }^{\dagger}$ Nazym Tuleushova, ${ }^{\dagger}$ Didier Cot, ${ }^{\dagger}$ Bertrand Rebiere,,${ }^{\ddagger}$ Valerie Bonniol,${ }^{\dagger}$ Julien Cambedouzou, ${ }^{\dagger}$ Sophie Tingry, ${ }^{\dagger}$ David Cornu, ${ }^{\dagger}$ and Yaovi Holade ${ }^{\dagger}, *$

†Institut Européen des Membranes, IEM UMR 5635, Univ Montpellier, ENSCM, CNRS, Montpellier, France.

Institut Charles Gerhardt Montpellier, UMR 5253, Univ Montpellier, ENSCM, CNRS, Montpellier, France *Corresponding author (Y.H): E-mail: yaovi.holade@enscm.fr

\begin{abstract}
There is currently a great interest for the development of electrochemical reactors to be implemented for the emerged world-class reactions of hydrogen evolution (HER), $\mathrm{CO}_{2}$ reduction $(\mathrm{CO} 2 \mathrm{RR})$ and $\mathrm{N}_{2}$ reduction $(\mathrm{N} 2 \mathrm{RR})$ in order to electro-synthesize high value-added chemicals. However, precisely how this could be achieved in a cheap and sustainable way remains a puzzle for scientists since the electrochemical kinetics of the oxygen evolution reaction (OER) is the major limitation. An increasing interest surrounds the development of low energy consumption electrolyzers capable of oxidizing selectively biomass-based organics instead of water for a dual production of chemicals (paired electrosynthesis). Also, the state-ofthe-art electrocatalyst is in a form of nanoparticles either dispersed on carbon supports or in liquids in the presence of stabilizers so that the nanoparticles' aggregation, detachment and performance loss are common. In this report, free-standing surfactant- and binder-free silvergold nanoporous and nanoalloyed catalysts are successfully synthesized via a simple and effective approach directly onto a gas diffusion electrode (GDE@AgAu). The physicochemical and electrocatalytic analysis show that the obtained ever reported activity and selectivity towards the glycerol electrooxidation reaction in alkaline media at metallic nanocatalysts is the result of the material's morphology and composition. Specifically, the onset potential is $E_{\text {onset }}$ $=0.3 \mathrm{~V}$ vs RHE and a record peak current density of $j_{\text {peak }}=18 \mathrm{~A} \mathrm{mg}_{\mathrm{Au}}{ }^{-1}\left(290 \mathrm{~mA} \mathrm{~cm}^{-2}\right)$ at GDE@AgAu in comparison with the tested commercial Au/C catalyst $\left(E_{\text {onset }}=0.7 \mathrm{~V}\right.$ vs RHE, $j_{\text {peak }}=2.8 \mathrm{~A} \mathrm{mgau}^{-1}$ or $44 \mathrm{~mA} \mathrm{~cm}{ }^{-2}$ ). Also, an unprecedented selectivity in glycerol electrooxidation towards two products of high interest, formate $(66 \%)$ and glycolate $(32 \%)$ has been recorded. GDE@AgAu is thus a potential substitute as anode materials for commercial
\end{abstract}


$\mathrm{Au}$ and Pt-based catalysts for efficient alcohols electroreforming in low energy consumption and cogeneration $\mathrm{H}_{2}, \mathrm{CO}_{2}$ or $\mathrm{N}_{2}$ electrolyzers. The present method that combines the direct growth, galvanic replacement and nanostructuration provides a smart route to carving out new designs in catalysts nanofabrication in order to target high electrocatalytic performance.

\section{Main text}

Electrolysis has been historically a powerful tool to produce a number of inorganic or organic materials. It has experienced a renaissance over the last decade with research efforts seeking low electrical energy consumption platforms for hydrogen evolution reaction (HER) and reaction of $\mathrm{CO}_{2}$ reduction $(\mathrm{CO} 2 \mathrm{RR})$ or $\mathrm{N}_{2}$ reduction $(\mathrm{N} 2 \mathrm{RR})$ in order to electro-synthesize compounds. The counter reaction, i.e., oxidation at the anode is typically the oxygen evolution reaction (OER) that not only occurs at high electrode potential of $E \geq 1.4 \mathrm{~V}$ vs reversible hydrogen electrode (RHE), but also uses precious/expensive catalysts (Ru, Ir, Co). ${ }^{1-3}$ Consequently, a significant portion of the energy required to electrochemically reduce $\mathrm{H}^{+} / \mathrm{H}_{2} \mathrm{O}$, $\mathrm{CO}_{2}$ or $\mathrm{N}_{2}$ to fuels and chemicals is typically consumed by the accompanying OER. ${ }^{4-7}$ Given their low oxidation potential ( $E=0-1 \mathrm{~V}$ vs RHE) compared to OER, the use of organic molecules instead of water molecules greatly lowers the input energy. ${ }^{5,6,8-10}$ Verma and coworkers reported alternative oxidative reactions using biodiesel-waste in order to achieve not only a low cell voltage, but also a high current density. ${ }^{5,6}$ More interesting, a tight control over the selectivity is extremely interesting in co-generation systems. Indeed, glycerol, a by-product from several industrial pathways such as biodiesel (100 kg of biodiesel release $10 \mathrm{~kg}$ of crude glycerol as side-product ${ }^{11}$ ) and fatty acids exceeds by far its consumption. So, a selective oxidation to specific products such as glycolic or formic acid can effectively cut down the cost of electrolysis. ${ }^{9,12}$ However, the simultaneous achievement of high activity and selectivity is a challenge. The mostly reported catalysts rely on the chemical or physical reduction of metallic precursors in the presence of a capping agent or surfactant, whereby catalysts are produced in the form of powder or liquid and a relatively high loading of metals of at least $0.1 \mathrm{mg} \mathrm{cm} \mathrm{cm}^{-2}$ is used during the catalysis. ${ }^{6,8}$ The used surfactants also limit the accessibility to the entire active sites. In addition, a binder, such as Nafion, is required to immobilize the NPs on a substrate (i.e. glassy carbon) prior to use, which adds a layer of complexity to the fabrication process as well as the loss of efficiency during operation. ${ }^{13}$

The combination of seed mediated growth and galvanic replacement methods enables to develop porous and alloyed structures comprising binary/ternary systems. ${ }^{14-23}$ For Au-based 
materials, Ag routinely acts as the template during the galvanic displacement since the standard redox potential of $\mathrm{Ag}^{+} / \mathrm{Ag}(0.80 \mathrm{~V}$ vs. standard hydrogen electrode (SHE)) is lower than that of $\mathrm{AuCl}_{4}{ }^{-} / \mathrm{Au}(1.00 \mathrm{~V}$ vs. SHE). While it was observed that residual Ag could locally stabilizes the surface atomic steps and increase the electrocatalysis, ${ }^{15}$ it is still unknown how to rationally incorporate Au during galvanic displacement directly on a 3D gas diffusion electrode (GDE) to subsequently optimize the activity, selectivity and durability of the nanoalloyed and nanoporous catalysts. In addition, the monitoring of the phenomenon of galvanic replacement to directly visualize the change in the galvanic potential and optimize the displacement duration has not yet reported. To address all these challenges, we report in this study a versatile surfactant- and binder-free method to directly grow Ag NPs onto a 3D GDE and further tightly perform a partial replacement of $\mathrm{Ag}$ by $\mathrm{Au}$ in order to fabricate free-standing electrocatalytic electrodes readyto-use. We found that the incorporation of chloride into the synthesis mixture is critical for tailoring highly porous $\mathrm{AgAu}$ decorated carbon paper electrode (GDE@AgAu), thus contributing to its intrinsic high electrocatalytic activity, selectivity and durability towards glycerol oxidation into glycolate (32\%) and formate $(66 \%)$.

To facilitate the implementation in the glycerol electrocatalysis for those AgAu nanoporous and nanoalloyed materials resulting from direct galvanic displacement onto a large surface electrode (GDE, at least $3 \mathrm{~cm} \times 3 \mathrm{~cm}$ ), we have designed the experiments shown in Scheme 1a. The experimental procedures are reported in the Electronic Supplementary Information (ESI $\dagger$ ). Herein, the pristine Ag NPs take the advantage of the metal-support interaction and do not have to be involved in a catalytic ink preparation process before immobilization on a substrate during various post-synthesis steps. This is an alternative to conventional galvanic displacement protocols, ${ }^{19,20,24}$ whereby the least noble NPs, here Ag, are initially prepared in solution before introduction in a replacement mixture made of the cation of the most noble metal, here $\mathrm{Au}$; the most used being $\mathrm{AuCl}_{4}^{-}$. Since the introduction of 1 atom of $\mathrm{Au}$ requires the removal of 3 atoms of $\mathrm{Ag}\left(3 \mathrm{Ag}+\mathrm{AuCl}_{4}^{-} \rightarrow 3 \mathrm{Ag}^{+}+\mathrm{Au}+4 \mathrm{Cl}^{-}\right)$, the process is expected to yield nanoporous structures. This illustration shows that the galvanic displacement of $\mathrm{Ag}$ atoms directly grown at the surface of a GDE's microfibers (template electrode, GDE@Ag) by those of Au leads to a nanoporous and nanoalloyed AgAu strongly attached to the support, and yields a free-standing catalyst (target electrode, GDE@AgAu). As shown in Scheme 1b, the further use of such GDE@AgAu electrode for glycerol electrooxidation reaction (GOE) can replace OER during $\mathrm{H}_{2}$ production by the electrocatalytic protons or water reduction reaction (HER) in aqueous media. More broadly, the illustration shows that any electrochemical reaction is always accompanied by a counter reaction; this dual electrosynthesis is termed "paired 
electrosynthesis". Hence, in aqueous media, an electro-reduction reaction such as HER, N2RR or $\mathrm{CO}_{2}$, etc. is always coupled with an electro-oxidation; OER or an organic molecule such as glycerol (refs. $[5,6]$ ). The overall required energy being the difference between the electrode potentials of the two processes, it becomes obvious that GOR enables lowering significantly the total consumed electrical energy.

Fig. Sla (ESI $\dagger$ ) of the control linear sweep voltammetry (LSV) demonstrates that the introduction of the ammonia solution $\left(\mathrm{NH}_{4} \mathrm{OH}\right)$ to form a $\left[\mathrm{Ag}\left(\mathrm{NH}_{3}\right)_{2}\right]^{+}$complex $(R=$ $n\left(\mathrm{NH}_{4} \mathrm{OH}\right) / n\left(\mathrm{Ag}^{+}\right)$, referred to as $\left.R x, x=0,4\right)$ is accompanied by the decrease of the reduction potential. In fact, the complexation of $\mathrm{Ag}^{+}$by $\mathrm{NH}_{3}$ leads to a strong decrease of the standard redox potential of $\mathrm{Ag}(\mathrm{I})$ from 0.80 to $0.37 \mathrm{~V}$ vs $\mathrm{SHE}$. This enables lowering the reduction kinetics in order to have a tight control on the seeds growth into homogeneous particles. The electrochemical program to grow directly Ag NPs onto GDE support of $3 \mathrm{~cm} \times 3 \mathrm{~cm}$ (one side) is composed of an OFF step $\left(I_{\mathrm{appl}}=0 \mathrm{~mA}, t_{\mathrm{OFF}}=5 \mathrm{~s}\right)$, an ON step $\left(I_{\mathrm{appl}}=-4.5 \mathrm{~mA}\right.$, i.e., $j_{\mathrm{appl}}=-$ $\left.0.5 \mathrm{~mA} \mathrm{~cm}^{-2}, t_{\mathrm{ON}}=5 \mathrm{~s}\right)$ and $N_{\text {cycles }}=126\left(0.15 \mathrm{mM} \mathrm{AgNO}_{3}\right)$ or $252\left(0.30 \mathrm{mM} \mathrm{AgNO}_{3}\right)$ as the total cycles to allow the seeds formation and electrode relaxation (Fig. S1b, ESI†). Fig. 1a shows the cyclic voltammetry $(\mathrm{CV})$ profiles of the as-synthesized CP-Ag electrodes at different ratios of $\mathrm{R} 0$ and $\mathrm{R} 4$. The oxidized silver during the forward scan is reduced during the backward scan at ca. $1.1 \mathrm{~V}$ vs RHE (the calibration curve vs the mercury-mercury oxide electrode (MOE) is reported in Fig. S2, ESI $\dagger$ ). The reduction peak area of $\mathrm{Ag}_{2} \mathrm{O}$ with a monolayer charge of 420 $\mu \mathrm{C} \mathrm{cm}^{-2}$ was considered to determine the electrochemically active surface area (ECSA inset of Fig. 1a). The ECSA of CP-Ag-R4 is $4.4 \times$ higher in comparison to CP-Ag-R0. This indicates that the introduction of a complexation step has a beneficial effect, which could be attributed to the reduction of the NPs size as well as a better distribution of NPs over the electrode surface. ${ }^{25,26} \mathrm{~A}$ further increase of the $\mathrm{AgNO}_{3}$ concentration is accompanied by an augmentation of the ECSA. We further examined numerous scanning electron microscopy (SEM) and energydispersive X-ray (EDX) images to determine the coverage of GDE's fibers by Ag NPs (Figs. 1b-f4). The SEM of the pristine GDE shows fibers (filled tubes) with a diameter of 7-9 $\mu \mathrm{m}$ (Fig. $1 \mathrm{~b}$ and Fig. S3, ESI $\dagger$ ). Since the thickness is $190 \mu \mathrm{m}$, it can be deduced that the entire 3D network is composed of ca. 27-21 layers of microfibers. We first observed that in the absence of $\mathrm{NH}_{3}$ ligand (Figs. 1c1-c2), the Ag NPs are randomly distributed on the surface of the microfibers with much agglomeration. Upon the introduction of $\mathrm{NH}_{3}$, homogenous $\mathrm{Ag} \mathrm{NPs}$ are obtained; about 10-50 $\mathrm{nm}$ for particles situated at the surface of the first layer of microfibers (Figs. 1d1-d2 and Fig. S4, ESI†). Figs. 1e1-e2 and Fig. S5, ESI $\dagger$ show the images for a higher concentration of $\mathrm{AgNO}_{3}$ where the surface coverage by Ag NPs is much important. The size of 
NPs is much smaller for those situated inside the 3D network of microfibers (Figs. S4 and S6, ESI $\dagger$ ). This suggests that NPs are preferentially deposited at the surface of the first three layers of the GDE on a total of approximately 25, which is similar to previous observations with metallic nanostructures obtained by chemical reduction onto GDE. ${ }^{13}$ In that case, it has been argued that the metal salt within the GDE interior diffuses towards the surface. The present observation can more rationally be explained by the applied electrical field between the working and counter electrodes in which the most exposed fibers allow the easy grow of particles. This means that the first step of the reduction of metal salts takes place at the external fibers' surface and then, the formation of the first seeds' layer of particles acts as an active site where a further reduction occurs. As shown in Figs. 1f1-f4 (and Figs. S3, S4-8, Table S1, ESI†), the maps of $\mathrm{Ag}$ and $\mathrm{C}$ confirm the homogeneous distribution.

The previous results demonstrate that we were able to manipulate the synthesis towards different localizations in the 3D structure of the GDE. So, having demonstrated the ability to use $\mathrm{NH}_{3}$ as a non-organic capping or surfactant agent to homogeneously grow Ag NPs directly onto a GDE support, we sought to study more carefully the conditions that enable a partial galvanic displacement of $\mathrm{Ag}$ atoms by those of $\mathrm{Au}$ for a better glycerol electrocatalysis. Since the GDE@Ag electrode has been obtained in $\mathrm{KNO}_{3}$ electrolyte, we firstly implemented the galvanic replacement in $\mathrm{KNO}_{3}$ solution (referred to as $\mathrm{GR}\left(\mathrm{KNO}_{3}\right)$ ) and secondly in pure water (referred to as $\mathrm{GR}\left(\mathrm{H}_{2} \mathrm{O}\right)$ ) to evaluate the impact on the replacement process. The objective was to mimic the GDE@Ag synthesis and determine whether Au(III) species could be injected directly into the Ag synthesis reactor once Ag NPs were formed or not. To evaluate the influence of the reaction duration on the growth and subsequently the morphology or electrocatalytic ability of particles, we quenched the reaction at different times. Figs. 2a-b show the CV profiles of the as-synthesized GDE@AgAu electrodes in the absence of glycerol. Those of the electrocatalytic performance in the presence of glycerol are depicted in Fig. 2c and Fig. S9 (ESI $\dagger$ ). The CVs show that the material with the largest area of the $\mathrm{Ag}_{2} \mathrm{O}$ reduction peak $\mathrm{GR}\left(\mathrm{KNO}_{3}\right)-30 \mathrm{~min}$ is not necessary the one which gives the highest peak current density during the electrocatalytic glycerol oxidation. Specifically, for the materials obtained by galvanic displacement in $\mathrm{KNO}_{3}$, the best kinetics and lowest charge transfer resistance (Fig. S9, ESI $\dagger$ ) at potential $E \leq 1$ vs $\mathrm{RHE}$ is $\mathrm{GR}\left(\mathrm{KNO}_{3}\right)-30 \mathrm{~min}$. For higher potentials, $\mathrm{GR}\left(\mathrm{KNO}_{3}\right)-10 \mathrm{~min}$ becomes the best with a peak current density of $j_{\mathrm{p}}=140 \mathrm{~mA} \mathrm{~cm}^{-2}$ in comparison to $j_{\mathrm{p}}=70 \mathrm{~mA}$ $\mathrm{cm}^{-2}$ for $\mathrm{GR}\left(\mathrm{KNO}_{3}\right)-30 \mathrm{~min}$. For the materials synthesized in water, $\mathrm{GR}\left(\mathrm{H}_{2} \mathrm{O}\right)-5 \mathrm{~min}$ is the most active catalyst with $j_{\mathrm{p}}=171 \mathrm{~mA} \mathrm{~cm}^{-2}$. A longer duration results in a decrease of the performance, presumably because of the oxidative etching of the formed nanostructures and the 
excess formation of the insoluble $\mathrm{AgCl} .^{27,28}$ The last hypothesis is supported by SEM and EDX observations (Figs. 2d-g, Fig. S10-14, ESI $\dagger$ ) that show more $\mathrm{AgCl}$ nanocubes. Quantitative EDX in Fig. 2h and Tables S2-5 (ESI $\dagger$ ) support the significant presence of chloride in the materials. The gold content is below 20 at $\%$. However, the galvanic replacement was targeting to fabricate a bimetallic AgAu material in which the gold content is about $80 \mathrm{at} \%$. Those results indicate that the maximum concentrations of chloride and silver ions in the final reaction solution lead to $\left[\mathrm{Ag}^{+}\right] \times\left[\mathrm{Cl}^{-}\right]$that falls below the solubility product of $\mathrm{AgCl}, K_{\mathrm{s}}=1.8 \times 10^{-10}$ at $20{ }^{\circ} \mathrm{C} .{ }^{23}$

Since the $\mathrm{AgCl}$ precipitate can be easily dissolved with a saturated $\mathrm{NaCl}$ solution (further called "brine solution") through the coordination reaction $\mathrm{AgCl}_{(\mathrm{s})}+3 \mathrm{Cl}^{-}$(aq) $\rightarrow \mathrm{AgCl}_{4}^{-}{ }_{(\mathrm{aq})},{ }^{23,29}$ we next tested the catalytic performance of three types of materials derived from $\mathrm{GR}\left(\mathrm{H}_{2} \mathrm{O}\right)$ 5min: the sample was thoroughly washed with $\mathrm{NaCl}$ after drying (referred to as $\mathrm{GR}\left(\mathrm{H}_{2} \mathrm{O}\right)$-driedwashed( $\mathrm{NaCl})$ ), the sample was immediately washed with $\mathrm{NaCl}$ (referred to as $\mathrm{GR}\left(\mathrm{H}_{2} \mathrm{O}\right)$ washed( $\mathrm{NaCl})$ ), or $\mathrm{NaCl}$ was directly dissolved in the galvanic displacement water (referred to as $\mathrm{GR}(\mathrm{NaCl})$ ). Fig. 3a shows the $\mathrm{CV}$ s normalized by the geometric surface area and those with the metal content are reported in Fig. 3b. A comparison is made with the commercial Vulcan$\mathrm{Au}(20 \mathrm{wt} \% \mathrm{Au} / \mathrm{C})$ and the homemade CP-Au (Fig. S15, ESI $\dagger)$. Among the tested conditions for the galvanic displacement, $j_{\mathrm{p}}=150,173$ and $290 \mathrm{~mA} \mathrm{~cm}{ }^{-2}$ for $\mathrm{GR}\left(\mathrm{H}_{2} \mathrm{O}\right)$-driedwashed( $\mathrm{NaCl}), \mathrm{GR}\left(\mathrm{H}_{2} \mathrm{O}\right)$-washed $(\mathrm{NaCl})$, and $\mathrm{GR}(\mathrm{NaCl})$, respectively. This suggests that the optimal surface composition and morphology of the $\mathrm{AgAu}$ particles after the galvanic displacement is reached when the latter is done directly in the presence of an excess amount of chloride. Controls experiments have been carried out with duration much shorter (2 min) and longer (10 min); and lower catalytic activities were observed. For CP-Au and Vulcan-Au, $j_{\mathrm{p}}=$ 84 , and $44 \mathrm{~mA} \mathrm{~cm}^{-2}$, respectively. Those peak current densities are $3.5 \times$ and $6.5 \times$ times lower in comparison to $\mathrm{GR}(\mathrm{NaCl})$. The bulk gold content determined by inductively coupled plasma optical emission spectrometry (ICP-OES) is $0.17 \mathrm{wt} \%$ for $\mathrm{GR}(\mathrm{NaCl})$ (i.e. $16 \mu \mathrm{g}_{\mathrm{Au}} \mathrm{cm}^{-2}$ ) and 0.75 wt. $\%$ for $\mathrm{CP}-\mathrm{Au}$ (i.e. $68 \mu \mathrm{g}_{\mathrm{Au}} \mathrm{cm}^{-2}$ ). So, in terms of the mass-activity, $j_{\mathrm{p}}=18.2,1.2$, and $2.8 \mathrm{~A} \mathrm{mg}_{\mathrm{Au}}{ }^{-1}$ for $\mathrm{GR}(\mathrm{NaCl}), \mathrm{CP}-\mathrm{Au}$, and Vulcan-Au, respectively. This represents about one order of magnitude increase of the catalytic activity for the material obtained by the galvanic displacement. Table S6 (ESI $\dagger$ ) gathers the comparative performance of relevant glycerol electrooxidation reaction on metallic catalysts in alkaline media from literature, wherein $j_{\mathrm{p}}$ is 20 to $70 \mathrm{~mA} \mathrm{~cm}^{-2}$ (geometric surface area), 0.2 to $4 \mathrm{~A} \mathrm{mg}_{\mathrm{Au}}{ }^{-1}$ (gold content) and the metal loading is relatively high, about $30-500 \mu \mathrm{g}_{\mathrm{Au}} \mathrm{cm}^{-2} \cdot 8,14,30-35$ Furthermore, a low onset potential ( $\left.E_{\text {onset }}\right)$ of ca. $0.3 \mathrm{~V}$ vs RHE was achieved with catalyst from $\mathrm{GR}(\mathrm{NaCl})$. It can thus be concluded 
that the electrocatalytic kinetics of the present GDE@AgAu free-standing electrocatalyst is higher than relevant values for the conventional chemically synthesized Au NPs by an order of magnitude and outperformed all data reported in the literature for metal and metal alloy-based electrocatalysts. It should be noted that ECSA cannot be precisely determined for a bimetallic $\mathrm{AgAu}$ electrode because there is a common potential window where the oxides of both involved metals are reduced and there is no reference value for the monolayer charge. Even though the ECSA of AgAu cannot be fairly evaluated for a comparison with the monometallic GDE@Au and Vulcan-Au materials, Fig. S16 (ESI $\dagger$ ) report an estimation of the performance by normalizing the current by the ECSA or both the ECSA and the Au weight. The results still show a significant enhancement of the performance for the bimetallic electrode. For $\mathrm{Au} / \mathrm{C}$ and GDE@AgAu, $j_{\mathrm{p}}=27 \mathrm{~mA} \mathrm{~cm}{ }_{\mathrm{Au}}\left(=3.3 \mathrm{~mA} \mathrm{~cm}{ }_{\mathrm{Au}}^{-2} \mu \mathrm{g}^{-1} \mathrm{Au}\right)$ and $92 \mathrm{~mA} \mathrm{~cm}{ }_{\mathrm{Au}}(=22.9 \mathrm{~mA}$ $\mathrm{cm}^{-2} \mathrm{Au} \mu \mathrm{g}^{-1} \mathrm{Au}$ ), respectively. In addition, ECSA is about 2, 11 and $20 \mathrm{~m}^{2} \mathrm{~g}^{-1} \mathrm{Au}$ for GDE@Au, commercial Vulcan-Au and GDE@AgAu, respectively. The enhanced electrocatalytic characteristics of GDE@AgAu are explained by the absence of any organic contaminants or protective ligands on their surface and by the possible porous and alloyed structure (will be fixed in the next sections). Indeed, Li et al. ${ }^{15}$ observed that residual Ag could stabilize the surface active sites during not only the dealloying of Au-Ag-Cu ternary alloy nanoparticles, but also the electrocatalytic oxidation of alcohols. Authors have observed that while the binding energy of the $\mathrm{Au} 4 \mathrm{f}$ peak remains essentially unchanged in regards to that of bulk $\mathrm{Au}$, both $\mathrm{Cu}$ $2 \mathrm{p}$ and $\mathrm{Ag} 3 \mathrm{~d}$ peaks significantly down-shift by 0.4 and $0.5 \mathrm{eV}$, respectively compared to their bulk materials. Thus, the present high efficiency could indicate that a fine balance has been achieved between the introduced $\mathrm{Au}$ and remaining $\mathrm{Ag}$ within the 3D materials to maximize the catalytic performance.

To gain a deeper understanding on the origin of the exceptional electrocatalytic performance of the $\mathrm{GR}(\mathrm{NaCl})$ material, we next utilized the electrochemical impedance spectroscopy (EIS, Fig. S17 (ESI $\dagger)$ ). The obtained results are shown in Fig. 3c in terms of the complex-plane Nyquist impedance plots and Fig. $3 \mathrm{~d}$ by the Tafel plots. The representative equivalent electrical circuit that best describes the electrocatalytic interface is $R_{\Omega}+Q_{\mathrm{CPE}} / / R_{\mathrm{ct}}$ and shown in Fig. 3c (Tables S7-9 (ESI $\dagger$ ) resume the fitted data) wherein $R_{\Omega}$ is the ohmic resistance or the uncompensated resistance, $R_{\mathrm{ct}}$ is the charge transfer resistance and $Q_{\mathrm{CPE}}$ is the constant phase element to model "imperfect" capacitance of the double-layer. ${ }^{36,37}$ The lowest values of $R_{\mathrm{ct}}$ (inversely proportional to the standard rate constant $k^{\circ}$, thus the exchange current density $j_{0}$ ) and Tafel slope (semi-quantitative indicator of charge-transfer kinetics and/or mechanisms) for CP-AgAu electrode confirm its excellent ability for fast electron transfer. Furthermore, the CVs 
collected at different scan rates $(v)$ in the presence of glycerol and the plot of $\log \left(j_{\mathrm{p}}\right)$ vs $\log (v)$ suggest that the overall reaction is limited by the adsorption, diffusion and electron transfer (Fig. S16, (ESI $\dagger)$ ). In fact, glycerol electrooxidation is a multi-proton and multi-electron transfer process, at least two electrons and two protons are transferred to electro-oxidize the primary or secondary alcohol function..$^{8,9,12,35}$ Hence, the previous outcomes demonstrate only our ability to regulate the kinetics of those processes. Suitability of GDE@AgAu electrodes for wider applications in the heterogeneous electrocatalysis may require lower number of electrons. So, we next theorized a same trend. To validate such hypothesis, we then electrochemically scrutinized the quasi-reversible redox probe $\mathrm{Fe}(\mathrm{CN})_{6}{ }^{3-} / \mathrm{Fe}(\mathrm{CN})_{6}{ }^{4-}$. Therefore, in order to provide a better qualitative and quantitative analysis of the electrochemical parameters, we used two different methods, namely the peak-to-peak separation $\Delta E_{\mathrm{p}}$ between the anodic and cathodic peaks on a CV (Fig. 3e) and the EIS at the open circuit potential (OCP) (Fig. 3f, Figs. S18-19 and Tables S10-11 (ESI $\dagger$ ). The above equivalent electrical circuit is modified to add in serial with $R_{\mathrm{ct}}$, a Warburg element $(W)$ to model the mass transport, i.e., diffusion. ${ }^{36,37} k^{\circ}\left(10^{-3}\right.$ $\left.\mathrm{cm} \mathrm{s}^{-1}\right)=0.3,0.7,2.0$ for $\mathrm{CP}, \mathrm{CP}-\mathrm{Ag}$ and $\mathrm{CP}-\mathrm{AgAu}$, respectively. Those data correspond to a significant enhancement of the electrochemical kinetics of CP by factor of 2.3 upon the growth of Ag and a factor of 6.7 following the galvanic displacement. The trend can be translated to as a decrease of $R_{\mathrm{ct}}$, which is confirmed by EIS where $R_{\mathrm{ct}}=1844,627,170$ and $38 \Omega \mathrm{cm}^{2}$ for CP, $\mathrm{CP}-\mathrm{Ag}, \mathrm{CP}-\mathrm{AgAu}$ and Pt-bulk, respectively. It features the ability to regulate the kinetics of electrodes as previously seen.

Having demonstrated the ability to use brine solution to improve the electrocatalytic efficiency of materials resulting from the galvanic displacement, we sought to study the composition and morphology more carefully. To these ends, we combined physical techniques of SEM, EDX, X-ray photoelectron spectroscopy (XPS) and small angle X-ray scattering (SAXS). For the sample GR( $\left.\mathrm{H}_{2} \mathrm{O}\right)$-washed( $\left.\mathrm{NaCl}\right)$, SEM images in Figs. 4a-b (and Fig. S20 $\left(\mathrm{ESI}+\dagger^{\dagger}\right)$ show the formation of porous donut-like nanostructures, which could be explained by the dissolution of $\mathrm{AgCl}$ so that the material reconstruction is not possible. For the $\mathrm{GR}(\mathrm{NaCl})$ material, SEM images in Figs. 4c-f (and Fig. S21, ESI $\dagger$ ) highlight the formation of a nanocage structure, which is similar to AgAu materials routinely obtained by the galvanic displacement, but in solution. ${ }^{15,19,20,23,24}$ The EDX maps of Figs. 4g-i show the homogeneous distribution of $\mathrm{Ag}$ and $\mathrm{Au}$ atoms, supported by EDX spectra (Figs. S22-23, ESI $\dagger$ ). The high-resolution XPS spectra of Au 4f and Ag 3d regions are depicted in Figs. 4j-k (and Fig. S24, ESI†), which underscore important current trends that the obtained metals are not oxidized. For the GR-5min, the doublet of gold metal are situated at $84.0 \mathrm{eV}$ for $\mathrm{Au} 4 \mathrm{f}_{7 / 2}$ and $87.7 \mathrm{eV}$ for $\mathrm{Au} 4 \mathrm{f}_{5 / 2}$ while 
those of $\mathrm{Ag} 3 \mathrm{~d}_{5 / 2}$ and $\mathrm{Ag} 3 \mathrm{~d}_{3 / 2}$ are situated at 367.9 and $373.9 \mathrm{eV}$, respectively. For the GR0min, silver metal is situated at $368.2 \mathrm{eV}$ for $\mathrm{Ag} 3 \mathrm{~d}_{5 / 2}$ and $374.2 \mathrm{eV}$ for $\mathrm{Ag} 3 \mathrm{~d}_{3 / 2}$. This indicates a negative shift of about $0.3 \mathrm{eV}$ in bimetallic material. Similar observations have been reported by $\mathrm{Li}$ et al. ${ }^{15}$ where the binding energy of the $\mathrm{Au} 4 \mathrm{f}$ peak remains unchanged while $\mathrm{Ag} 3 \mathrm{~d}$ peak down-shifts by $0.5 \mathrm{eV}$. So, it appears that in addition to the highly nanoporous structure, both $\mathrm{Ag}$ and $\mathrm{Au}$ elements are forming an alloyed phase in which there is a strong electronic interaction between silver and gold. Quantitative data from EDX (Figs. S22-23, Tables S12-13 $($ ESI $\dagger))$ are displayed in Fig. 41 and compared with the results from XPS in the case of $\mathrm{GR}(\mathrm{NaCl})$. When the galvanic replacement is performed in $\mathrm{H}_{2} \mathrm{O}$ and then immediately washed by $\mathrm{NaCl}$, the remaining chloride represents 5 at\% (considering $\mathrm{Ag}, \mathrm{Au}$ and $\mathrm{Cl}$ species). By carrying out directly in $\mathrm{NaCl}$, all the chloride is removed and the final atomic ratio is $\mathrm{Ag} / \mathrm{Au}=$ 10:90 by XPS and 13:87 by EDX. Hence, the results testify that we successfully realized the partial galvanic replacement of Ag atoms by those of Au directly at the surface of free-standing GDE. SAXS analyses were conducted on GDE, GDE@Ag and GDE@AgAu (Figs. 4m-n). Fig. $4 \mathrm{n}$ shows that the graphite (002) peak at $18.8 \mathrm{~nm}^{-1}$ overlap well in all samples, meaning that the graphitic carbon amount remains constant. The (111) Bragg peak from Ag is visible at $\sim 27 \mathrm{~nm}^{-}$ ${ }^{1}$ for GDE@Ag, but absent in GDE@AgAu. This highlights the alteration of the Ag crystalline structure. SAXS profiles show a Porod regime in the $0.5-3 \mathrm{~nm}^{-1}$ range, revealing sharp interfaces at nanoscale. Interestingly, GDE@AgAu shows high intensity for scattering vectors lower than $0.4 \mathrm{~nm}^{-1}$. This confirms the presence of new nanoscale objects. Conclusively, the combination of nanoscale defects in the channels, pore walls and bifunctional/ligand effects $^{15,31,32,35,38,39}$ explained the substantial improvement of the catalysis of the GDE@AgAu material.

To gain deeper insights about the galvanic displacement in brine solution and why the reaction duration of 5 min gave the best electrocatalytic activity, we designed an experiment to determine the electrode potential of CP-Ag following the addition of $\mathrm{AuCl}_{4}{ }^{-}$. Fig. 5a shows the OCP profiles for two different CP-Ag free-standing electrodes. Initially, OCP is about $-0.13 \mathrm{~V}$ vs $\mathrm{Ag} / \mathrm{AgCl}$. Upon the one-pot injection of $\mathrm{Au}(\mathrm{III})$, there is a first sharp increase towards +0.03 $\mathrm{V}$ vs $\mathrm{Ag} / \mathrm{AgCl}$, followed by a stabilization before a second important increase to yield a steadystate $\mathrm{OCP}=+0.69 \mathrm{~V}$ vs $\mathrm{Ag} / \mathrm{AgCl}$. Those three characteristic domains could be assigned to the following processes. The first is attributed to an undefined potential of an Ag electrode immerged in a not degassed $\mathrm{NaCl}$ solution ( $\mathrm{OCP}=-0.13 \mathrm{~V}$ vs $\mathrm{Ag} / \mathrm{AgCl}$ ). The second is a fabricated "pseudo $\mathrm{Ag} / \mathrm{AgCl}$ electrode" after the first galvanic displacement so that the recorded OCP is just the potential difference between two $\mathrm{Ag} / \mathrm{AgCl}$ reference electrodes (that is why 
$\mathrm{OCP}$ is quiet zero). Given the composition of $\mathrm{Ag}_{10} \mathrm{Au}_{90}$ after the galvanic replacement, the third is the potential of an "Au-like" electrode immerged in a not degassed $\mathrm{NaCl}$ solution containing $\mathrm{AuCl}_{4}{ }^{-}$since $E^{\circ}\left(\mathrm{AuCl}_{4}{ }^{-} / \mathrm{Au}\right)=1.0 \mathrm{~V}$ vs SHE , about $0.8 \mathrm{~V}$ vs $\mathrm{Ag} / \mathrm{AgCl}$. The exact origin of the spikes is unknown, but they could be the consequence of a mass substitution of Ag atoms as well as the nanostructuration of particles in the presence of $\mathrm{O}_{2}$ and $\mathrm{Cl}^{-}$; those species form a strong oxidative etching agent. ${ }^{21}$ From Fig. 5a, it becomes clear that $5 \mathrm{~min}$ is the optimal duration for the galvanic displacement in a brine solution, which supports the previous results. We further run the long-term bulk glycerol electrolysis to simultaneously evaluate the reaction selectivity as well as the accelerated ageing on the catalyst's morphology and composition. Fig. $5 \mathrm{~b}$ shows the evolution of the oxidation current $(I)$ and quantity of electricity $(Q)$ during a $3 \mathrm{~h}$ electrolysis. Given the 3D nanostructure of the GDE@AgAu material, we utilized a programmed potential electrolysis (PPE) to facilitate the mass transport by repeating potentiostatic discharging cycles of $10 \mathrm{~s} \mathrm{ON}\left(E=E_{\text {appl }}=1.246 \mathrm{~V}\right.$ vs RHE, no iR-drop correction) and $10 \mathrm{~s}$ OFF ( $E=\mathrm{OCP})$. The results show a good stability. Fig. 5c displays the chromatograms obtained from HPLC analysis (Table S14, ESI $\dagger$ ) while Fig. 5d shows the selectivity trend for identified products after electrolysis; Fig. S25 (ESI $\dagger$ ) for the standards. While many products used to be obtained at metallic electrocatalysts, ${ }^{35,40-42}$ only two main products have been obtained in this study, for instance formic and glycolic acids at the selectivity of 66 and $32 \%$, respectively (oxalic acid is $1.8 \%$, glyceric acid is $0.7 \%$ and tartronic acid $0.1 \%$ ). The determined exchanged number of electrons that are transferred is about 6 , which is in agreement with the production of the carboxylate forms of those products in alkaline media so that the faradaic yield is about $86 \%$. Based on chromatographic analyses and in order to account the glycerol electrooxidation, Scheme S1 was proposed for glycerol electrooxidation on the as-synthesized silver-gold nanoporous and nanoalloyed nanocatalysts in alkaline media. Given the high selectivity towards formate, we postulated that it was produced by two parallel pathways, one from glycerate and another from glycolate. Finally, Figs. 5e-j show the postmortem SEM, HRSEM and EDX after the electrolysis. Interestingly, HRSEM analyses do not show any morphology modification; hence the material keeps its nanoporous structure. EDX spectra and quantitative data are reported in Fig. S26 and Table S15 (ESI $\dagger$ ). The atomic ratio $\mathrm{Ag} / \mathrm{Au}$ is about 18:82, a slight change when compared to raw material (13:87). It can thus be summed up that the electrode exhibits good electrochemical stability.

\section{Conclusions}


In summary, a novel class of electrode material, composed of a gas diffusion electrode (GDE) decorated by metallic silver-gold nanoporous and nanoalloyed particles, was fabricated to selectively electro-oxidize glycerol in alkaline media. The newly developed convenient approach without introducing any template or organic surfactant enables simplifying the various preparation and post-synthesis steps. The nanoparticles were directly attached to the GDE so that there was no need to prepare a catalytic ink, which enabled bypassing the use of binders, avoiding active sites obstruction, minimizing nanoparticles detachment from the electrode, and preventing particles agglomeration. Owing to its nanoporous and nanoalloyed features, the as-synthesized free-standing GDE@AgAu electrode demonstrated a drastic enhancement of the electrocatalytic performance with an onset potential below $0.5 \mathrm{~V}$ vs RHE and a record current density of $18 \mathrm{~A} \mathrm{mg}_{\mathrm{Au}}{ }^{-1}\left(290 \mathrm{~mA} \mathrm{~cm}{ }^{-2}\right)$. This is at least one order of magnitude larger than the tested commercial $\mathrm{Au} / \mathrm{C}$ catalyst under our conditions and other reported mono- and multi-metallic electrocatalysts. The material also exhibited an unprecedented selectivity in glycerol electrooxidation, whereby only two products of high interest, formate (66\%) and glycolate (32\%) have been obtained. This study contributes toward advances in the design of efficient and low energy input anode to be coupled with emerging hydrogen evolution (HER), $\mathrm{CO}_{2}$ reduction reaction $(\mathrm{CO} 2 \mathrm{RR})$ or $\mathrm{N}_{2}$ reduction reaction $(\mathrm{N} 2 \mathrm{RR})$ in order to electro-synthesize high value-added fuels and chemicals.

\section{Author Contributions}

Y. H. conceived the idea and designed the experiments. R. B., N. T. and Y. H. performed materials synthesis and electrochemical measurements. D. C. (Cot) and B. R. performed SEM and EDX measurements. V. B performed chromatography measurements. J. C. performed SAXS analyses and data treatment. S. T., D. C. (Cornu), and Y. H. supervised the study. Y. H wrote the manuscript and all of the authors edited the manuscript before submission.

\section{Conflicts of interest}

The authors declare no competing financial interest.

\section{Acknowledgements}

This work has been partially funded by the French National Agency (ANR) through the LabEx CheMISyst (ANR-10-LABX-05-01) and the European Institute of Membranes of Montpellier through the Exploratory Project COGENFC (PAT-Axis-Energy-2018). The authors thank J. Causse for assistance in SAXS operation and Valerie Flaud for XPS measurements. 


\section{Notes and references}

1. V. R. Stamenkovic, D. Strmcnik, P. P. Lopes and N. M. Markovic, Nat. Mater., 2017, 16, 5769.

2. Z. W. Seh, J. Kibsgaard, C. F. Dickens, I. Chorkendorff, J. K. Nørskov and T. F. Jaramillo, Science, 2017, 355, eaad4998.

3. L. C. Seitz, C. F. Dickens, K. Nishio, Y. Hikita, J. Montoya, A. Doyle, C. Kirk, A. Vojvodic, H. Y. Hwang, J. K. Norskov and T. F. Jaramillo, Science, 2016, 353, 1011-1014.

4. A. Tatin, C. Comminges, B. Kokoh, C. Costentin, M. Robert and J.-M. Savéant, Proc. Natl. Acad. Sci., 2016, 113, 5526-5529.

5. A. Bardow and M. Wessling, Nat. Energy, 2019, 4, 440-441.

6. S. Verma, S. Lu and P. J. A. Kenis, Nat. Energy, 2019, 4, 466-474.

7. R. D. Milton, S. Abdellaoui, N. Khadka, D. R. Dean, D. Leech, L. C. Seefeldt and S. D. Minteer, Energy Environ. Sci., 2016, 9, 2550-2554.

8. J. González-Cobos, S. Baranton and C. Coutanceau, ChemElectroChem, 2016, 3, 1694-1704.

9. C. Coutanceau and S. Baranton, Wiley Interdiscip. Rev.: Energy Environ., 2016, 5, 388-400.

10. C. Lamy, T. Jaubert, S. Baranton and C. Coutanceau, J. Power Sources, 2014, 245, 927-936.

11. M. Pagliaro, R. Ciriminna, H. Kimura, M. Rossi and C. Della Pina, Angew. Chem. Int. Ed., 2007, 46, 4434-4440.

12. Y. Holade, K. Servat, S. Tingry, T. W. Napporn, H. Remita, D. Cornu and K. B. Kokoh, ChemPhysChem, 2017, 18, 2573-2605.

13. Y. Holade, D. P. Hickey and S. D. Minteer, J. Mater. Chem. A, 2016, 4, 17154-17162.

14. H. Xu, J. Wang, B. Yan, K. Zhang, S. Li, C. Wang, Y. Shiraishi, Y. Du and P. Yang, Nanoscale, 2017, 9, 12996-13003.

15. G. G. Li, Y. Lin and H. Wang, Nano Lett., 2016, 16, 7248-7253.

16. M. Xu, Y. Sui, G. Xiao, X. Yang, Y. Wei and B. Zou, Nanoscale, 2017, 9, 2514-2520.

17. C. Xu, Q. Hao and H. Duan, J. Mater. Chem. A, 2014, 2, 8875-8880.

18. H. M. Song, D. H. Anjum, R. Sougrat, M. N. Hedhili and N. M. Khashab, J. Mater. Chem., 2012, 22, 25003-25010.

19. S. M. Alia, Y. S. Yan and B. S. Pivovar, Catal. Sci. Technol., 2014, 4, 3589-3600.

20. A. G. M. da Silva, T. S. Rodrigues, S. J. Haigh and P. H. C. Camargo, Chem. Commun., 2017, 53, 7135-7148.

21. A. Ruditskiy and Y. Xia, ACS Nano, 2017, 11, 23-27.

22. L. Zhang, L. T. Roling, X. Wang, M. Vara, M. Chi, J. Liu, S.-I. Choi, J. Park, J. A. Herron, Z. Xie, M. Mavrikakis and Y. Xia, Science, 2015, 349, 412-416.

23. Y. Sun and Y. Xia, J. Am. Chem. Soc., 2004, 126, 3892-3901. 
24. S. E. Skrabalak, L. Au, X. Li and Y. Xia, Nat. Protocols, 2007, 2, 2182-2190.

25. L. Kvitek, R. Prucek, A. Panacek, R. Novotny, J. Hrbac and R. Zboril, J. Mater. Chem., 2005, 15, 1099-1105.

26. A. Panáček, L. Kvítek, R. Prucek, M. Kolář, R. Večeřová, N. Pizúrová, V. K. Sharma, T. j. Nevěčná and R. Zbořil, J. Phys. Chem. B, 2006, 110, 16248-16253.

27. Y. Xiong, H. Cai, B. J. Wiley, J. Wang, M. J. Kim and Y. Xia, J. Am. Chem. Soc., 2007, 129, $3665-3675$.

28. Y. Xiong, J. Chen, B. Wiley, Y. Xia, S. Aloni and Y. Yin, J. Am. Chem. Soc., 2005, 127, 7332-7333.

29. I. Lampre, P. Pernot and M. Mostafavi, J. Phys. Chem. B, 2000, 104, 6233-6239.

30. Z. Chen, C. Liu, X. Zhao, H. Yan, J. Li, P. Lyu, Y. Du, S. Xi, K. Chi, X. Chi, H. Xu, X. Li, W. Fu, K. Leng, S. J. Pennycook, S. Wang and K. P. Loh, Adv. Mater., 2019, 31, 1804763.

31. S. Li, J. Lai, R. Luque and G. Xu, Energy Environ. Sci., 2016, 9, 3097-3102.

32. W. Hong, C. Shang, J. Wang and E. Wang, Energy Environ. Sci., 2015, 8, 2910-2915.

33. Y. Zhou, Y. Shen and J. Xi, Appl. Catal. B: Env., 2019, 245, 604-612.

34. H. Xu, J. Wei, M. Zhang, C. Wang, Y. Shiraishi, J. Guo and Y. Du, J. Mater. Chem. A, 2018, 6, 24418-24424.

35. A. Zalineeva, A. Serov, M. Padilla, U. Martinez, K. Artyushkova, S. Baranton, C. Coutanceau and P. B. Atanassov, J. Am. Chem. Soc., 2014, 136, 3937-3945.

36. A. Lasia, Electrochemical Impedance Spectroscopy and its Applications, Springer-Verlag, New York, NY, USA, 2014.

37. M. E. Orazem and B. Tribollet, Electrochemical Impedance Spectroscopy, John Wiley \& Sons, Inc. , Hoboken, New Jersey, USA, 2 edn., 2017.

38. S. T. Nguyen, H. M. Law, H. T. Nguyen, N. Kristian, S. Wang, S. H. Chan and X. Wang, Appl. Catal. B: Env., 2009, 91, 507-515.

39. J. Wang, F. Chen, Y. Jin and Y. Lei, ACS Appl. Mater. Interfaces., 2018, 10, 6276-6287.

40. J. Qi, N. Benipal, C. Liang and W. Li, Appl. Catal. B: Env., 2016, 199, 494-503.

41. Z. Zhang, L. Xin and W. Li, Appl. Catal. B: Env., 2012, 119-120, 40-48.

42. M. S. E. Houache, K. Hughes and E. A. Baranova, Sustainable Energy Fuels, 2019, 3, 18921915. 

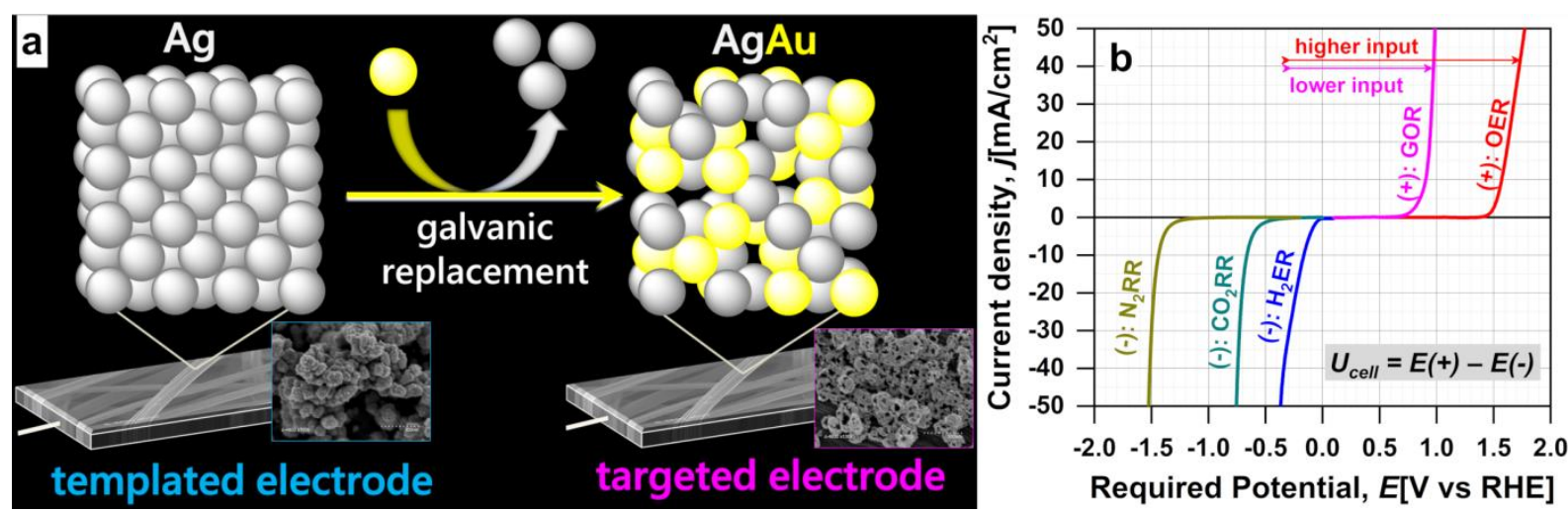

Scheme 1. Sketch of electrode fabrication for the bioeconomy production of value - added fuels or chemicals. (a) Schematic illustration of the process of galvanic displacement (GR) of Ag atoms by those of Au directly at the surface of a gas diffusion electrode (GDE), leading to nanoporous structures. (b) Typical half-cell polarization curves illustrating the working principle of different scenarios of cogenerative electrosynthesis that couple a process at negative electrode (cathode, $(-)$ ) to one at positive electrode (anode, $(+))$.
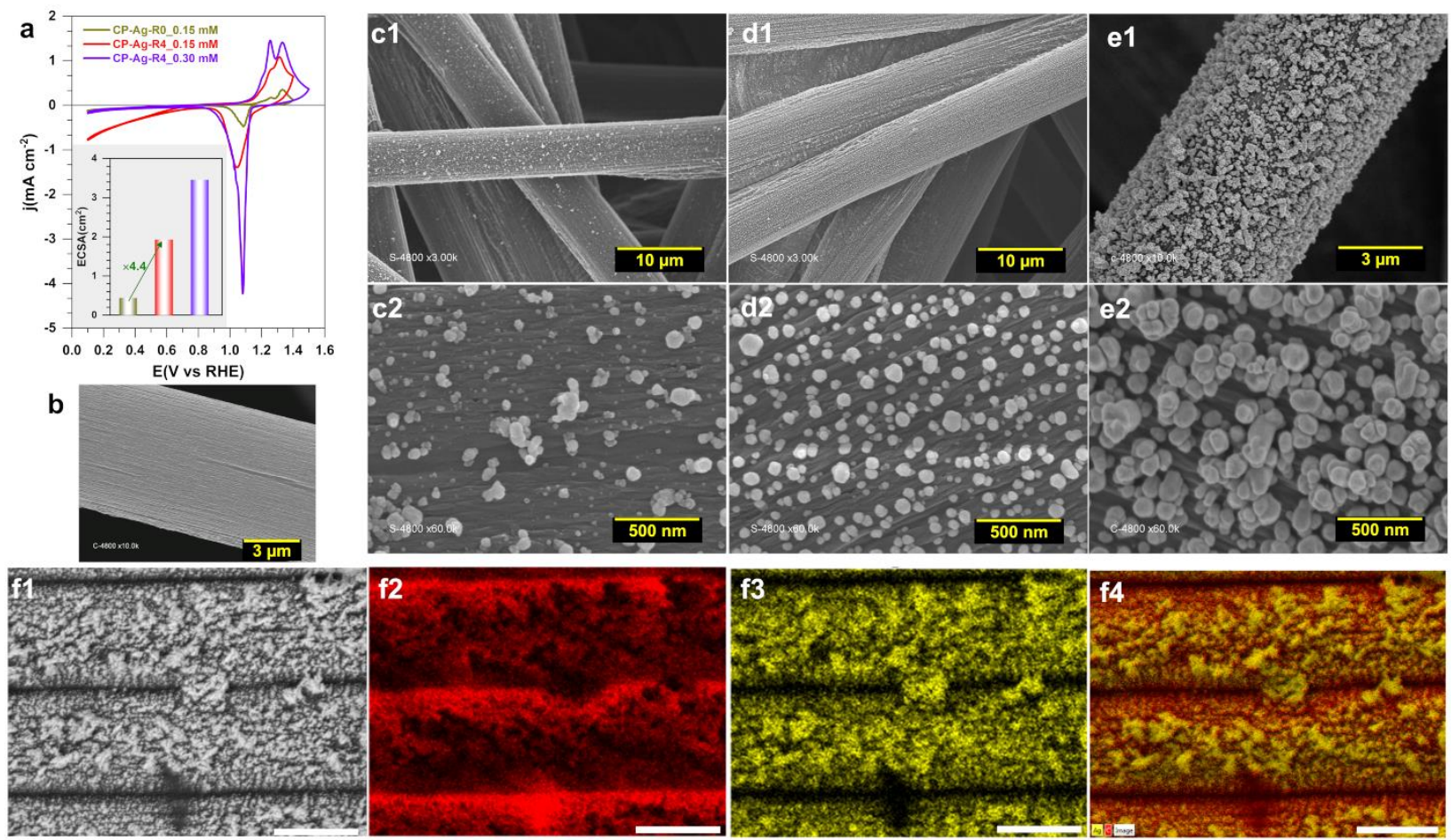

Fig. 1. Characterization of template electrodes. (a) iR-free $\mathrm{CVs}$ recorded at $50 \mathrm{mV} \mathrm{s}^{-1}$ in $1 \mathrm{M} \mathrm{KOH}$ and $25{ }^{\circ} \mathrm{C}$ (in inset the profiles of the corresponding ECSA) for the as-synthesized materials at $\mathrm{AgNO}_{3}$ concentration of 0.15 and $0.30 \mathrm{mM}$ for different ratios $R\left(=\mathrm{n}\left(\mathrm{NH}_{4} \mathrm{OH}\right) / \mathrm{n}\left(\mathrm{AgNO}_{3}\right)\right)=0$ and 4 . SEM micrographs of $\mathrm{Ag}$ grown onto a GDE for different ratios: (c1, c2) $R=0$ and $0.15 \mathrm{mM} \mathrm{AgNO}_{3},(\mathrm{~d} 1, \mathrm{~d} 2)$ $R=4$ and $0.15 \mathrm{mM} \mathrm{AgNO}_{3}$; (e1, e2) $R=4$ and $0.30 \mathrm{mM} \mathrm{AgNO}_{3}$. (fl-f4) SEM and EDX elemental maps (scale bar=5 $\mu \mathrm{m}$ ) for GDE@Ag obtained with $R=4$ and $0.30 \mathrm{mM} \mathrm{AgNO}_{3}$ : (f2) C, (f3) $\mathrm{Ag}$, (f4) $\mathrm{C}+\mathrm{Ag}$. 

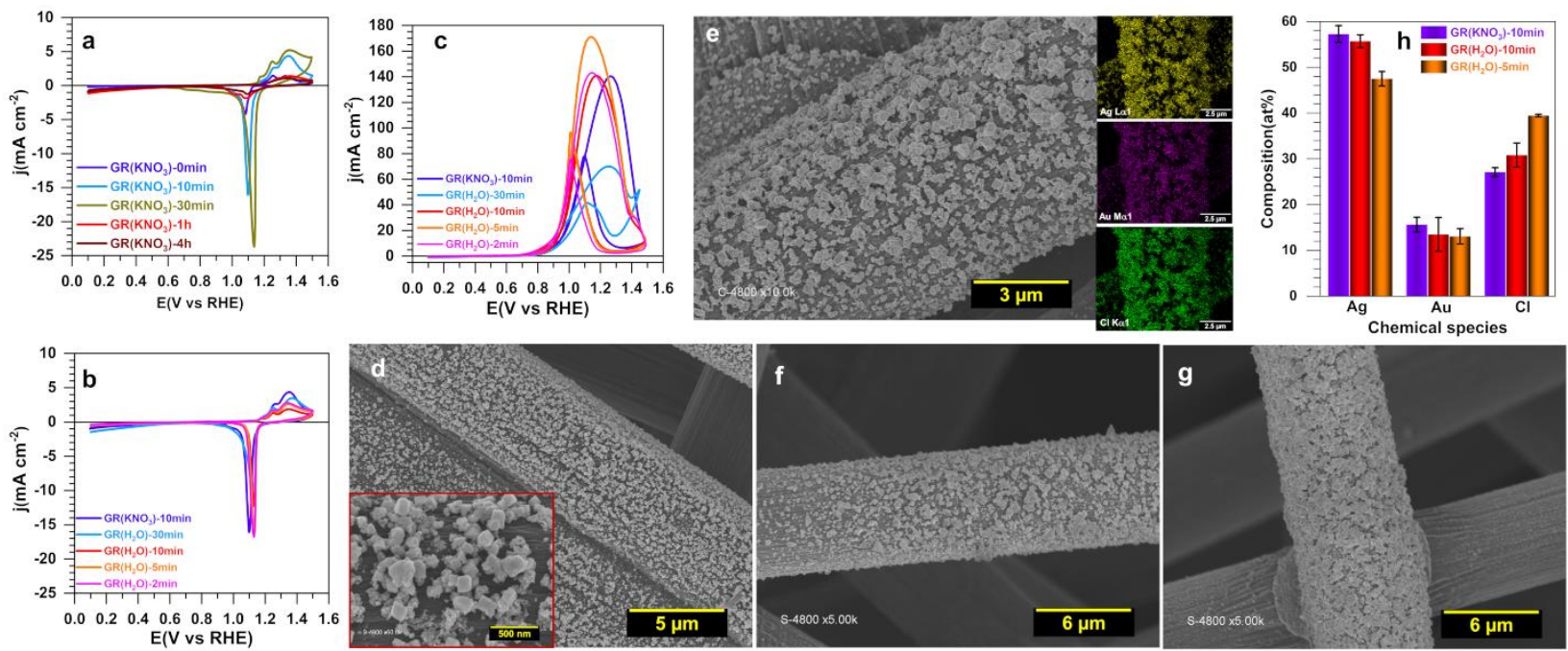

Fig. 2. Characterization and performance of GDE@AgAu materials obtained by galvanic displacement (GR) performed in $\mathrm{KNO}_{3}$ or $\mathrm{H}_{2} \mathrm{O}$. (a) iR-free CVs $\left(50 \mathrm{mV} \mathrm{s}^{-1}, 1 \mathrm{M} \mathrm{KOH}, 25^{\circ} \mathrm{C}\right)$ for GR performed in $\mathrm{KNO}_{3}$. iR-free CVs $\left(50 \mathrm{mV} \mathrm{s}^{-1}, 1 \mathrm{M} \mathrm{KOH}, 25^{\circ} \mathrm{C}\right)$ in the absence (b) and presence (c) of $0.1 \mathrm{M}$ glycerol for GR performed in $\mathrm{KNO}_{3}$ or $\mathrm{H}_{2} \mathrm{O}$. SEM images for GR performed in $\mathrm{KNO}_{3}$ : (d) $4 \mathrm{~h}$ and (e) $30 \mathrm{~min}$ and its corresponding EDX elemental maps ( $\mathrm{Ag}, \mathrm{Au}$, and $\mathrm{Cl}$ from top to down). SEM images for GR performed in $\mathrm{H}_{2} \mathrm{O}$ : (f) $10 \mathrm{~min}$ and (g) $5 \mathrm{~min}$. (h) Atomic composition from EDX maps: error bars represent $1 \mathrm{SD}(n \geq 3)$.
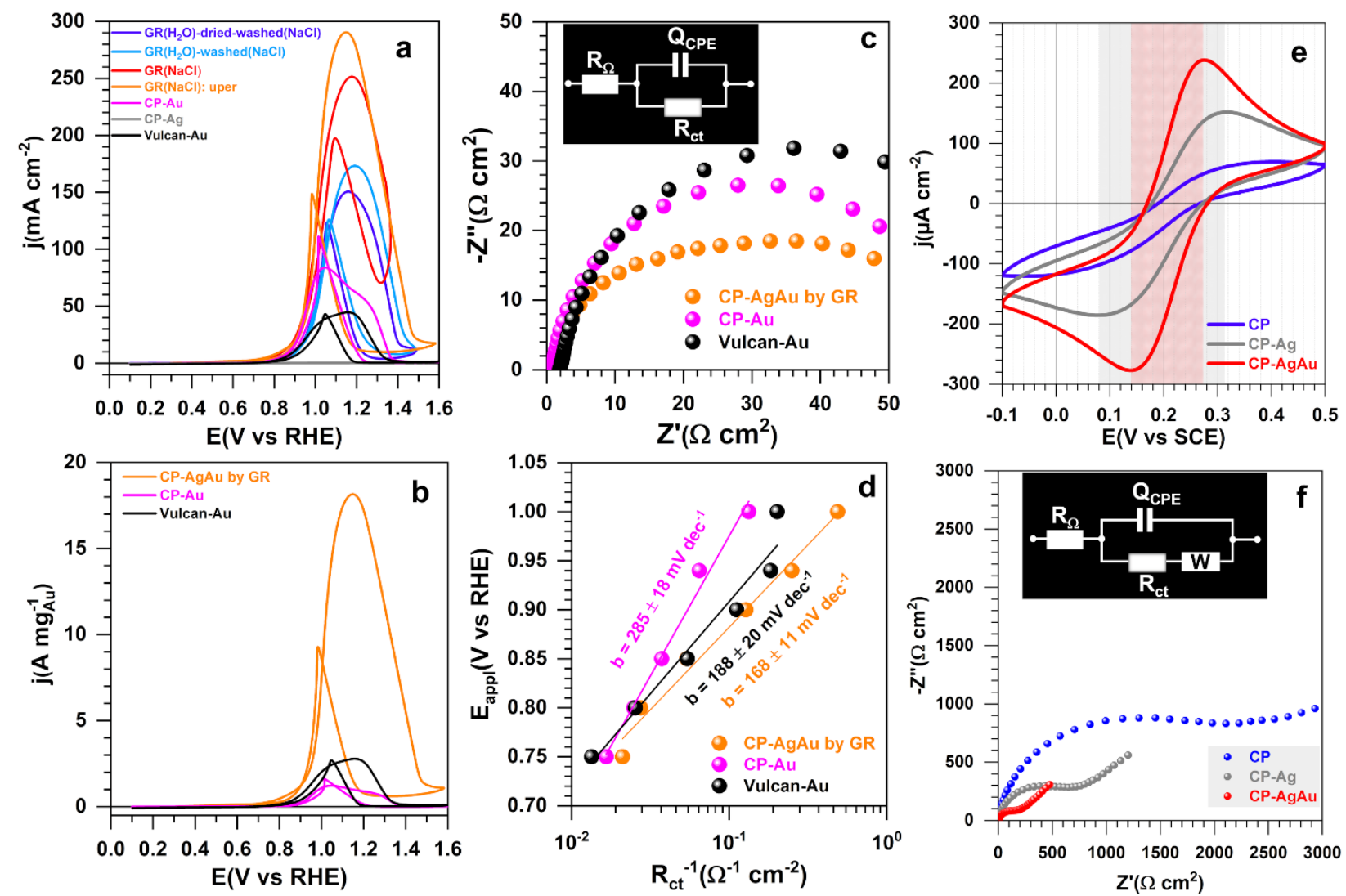

Fig. 3. Comparative performance of the commercial Vulcan-Au and the as-synthesized CP-Ag, CP-Au, CP-AgAu materials obtained by galvanic displacement (GR) in either $\mathrm{H}_{2} \mathrm{O}$ before washing by a brine 
solution or directly in the brine solution. iR-free CVs $\left(50 \mathrm{mV} \mathrm{s}^{-1}, 1 \mathrm{M} \mathrm{KOH}, 0.1 \mathrm{M}\right.$ glycerol, $\left.25^{\circ} \mathrm{C}\right)$ : (a) Normalized by the geometric surface area (b) Normalized by the Au weight, (c) Complex-plane Nyquist impedance at $E_{\text {appl }}=0.75 \mathrm{~V}$ vs RHE (inset shows the equivalent electrical circuit of $\mathrm{R}_{\Omega}+\mathrm{Q}_{\mathrm{CPE}} / \mathrm{R}_{\mathrm{ct}}$ ) and (d) Tafel plots by $\mathrm{R}_{\text {ct. }}$ (e) iR-free CVs $\left(10 \mathrm{mV} \mathrm{s}^{-1}, 0.5 \mathrm{M} \mathrm{KNO}_{3}+1 \mathrm{mM} \mathrm{K}_{3}\left[\mathrm{Fe}(\mathrm{CN})_{6}\right], 2{ }^{\circ} \mathrm{C}\right)$ and the corresponding (f) Complex-plane Nyquist impedance at $\mathrm{E}_{\text {appl }}(=\mathrm{OCP})=0.25 \mathrm{~V}$ vs SCE (inset shows the equivalent electrical circuit of $\mathrm{R}_{\Omega}+\mathrm{Q}_{\mathrm{CPE}} /\left(\mathrm{R}_{\mathrm{ct}}+\mathrm{W}\right)$.
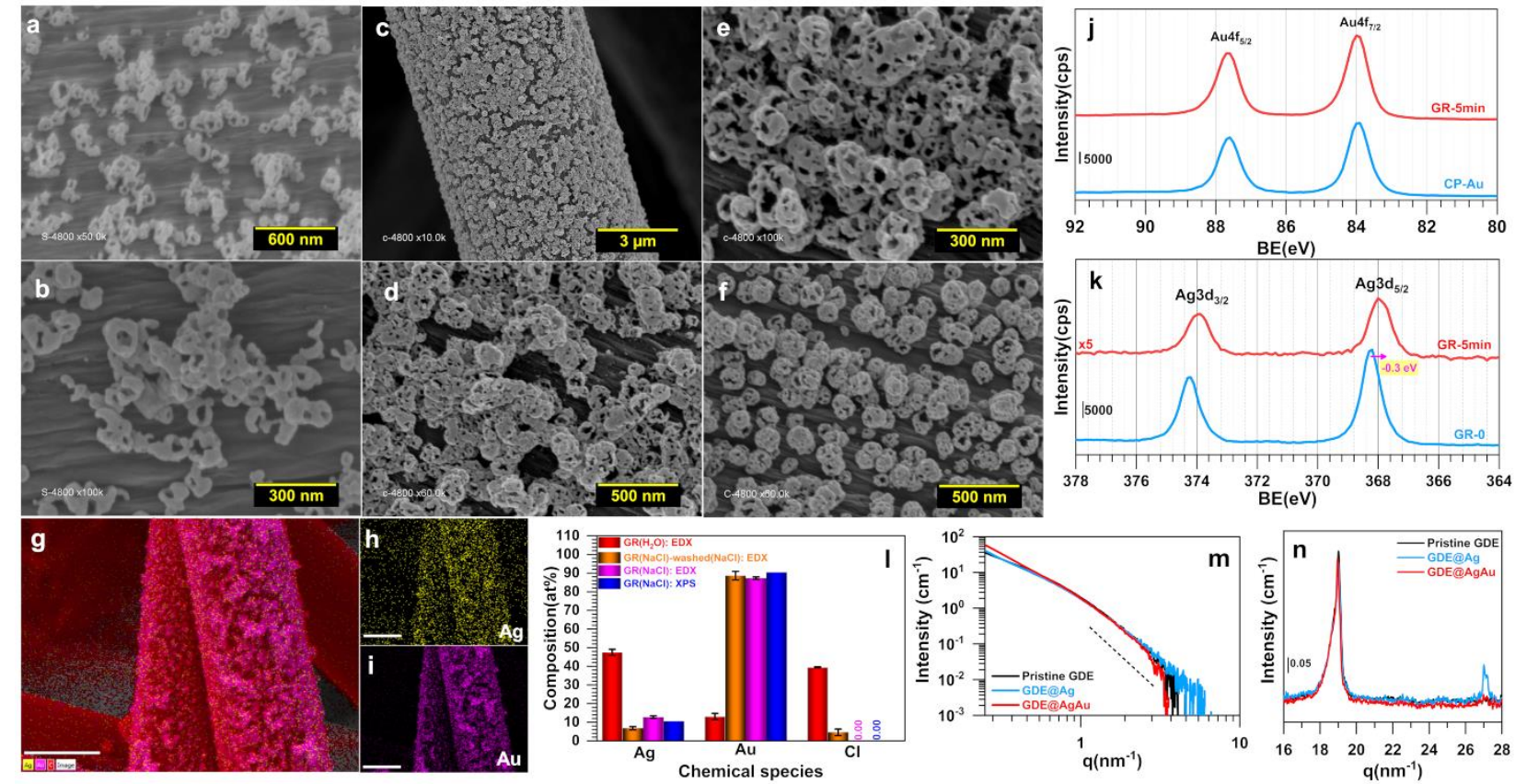

Fig. 4. Morphological and compositional characterization of the as-synthesized GDE@AgAu materials by the galvanic replacement (GR). ( $a, b)$ SEM/HRSEM images of the as-synthesized GDE@AgAu material by GR performed in $\mathrm{H}_{2} \mathrm{O}(5 \mathrm{~min})$ and subsequently washed with a brine solution, referred to as GR $\left(\mathrm{H}_{2} \mathrm{O}\right)$-washed( $\left.\mathrm{NaCl}\right)$. (c-f) SEM/HRSEM images of the as-synthesized GDE@AgAu material by GR performed in a brine solution, referred to as GR(NaCl). (g-i) EDX mapping (scale bar $=5 \mu \mathrm{m}$ ) of GR(NaCl) material: (g) Au+Ag, (h) Ag, and (i) Au. (j, k) High-resolution XPS spectra of GR(NaCl) material: (j) Au 4f and (k) Ag 3d. (1) Atomic composition from EDX and XPS: error bars represent 1 SD $(n \geq 3)$. (m, n) SAXS patterns of the pristine GDE (black), GDE@Ag (blue), and GDE@AgAu (red). The black dashed line represents a q-4 Porod power law: Panel (n) is a magnification of the wide angles. 

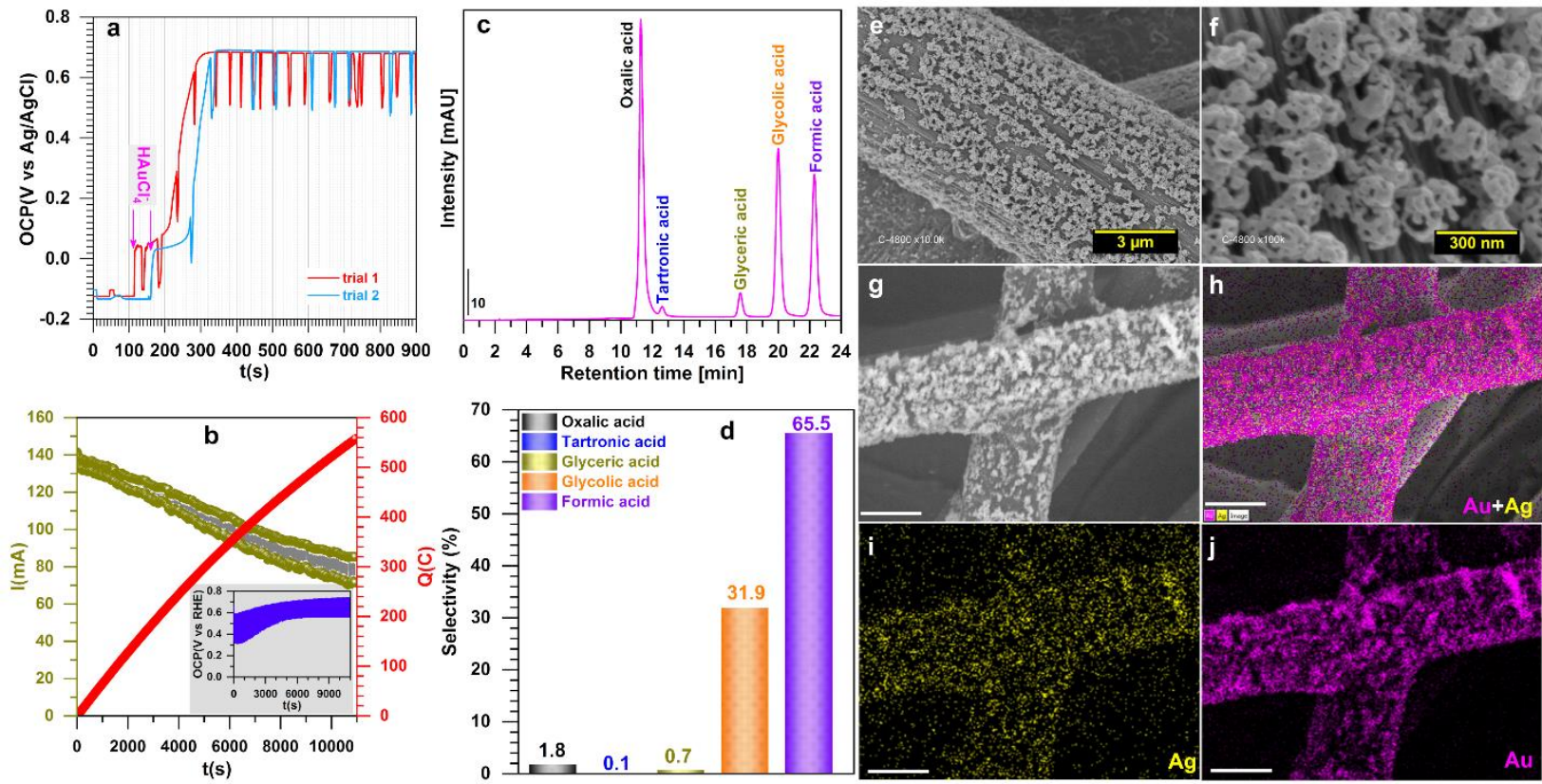

Fig. 5. Study of the galvanic replacement (GR) in the brine solution and the efficiency of the obtained GDE@AgAu material. (a) OCP profiles recorded during GR (3.5 M NaCl, room temperature, gentle stirring) at two different CP-Ag free-standing electrodes. (b) Evolution of the oxidation current ( $I$, left $y$-axis) and quantity of electricity ( $Q$, right $y$-axis) during a $3 \mathrm{~h}$ long-term electrolysis $(1 \mathrm{M} \mathrm{KOH}, 0.1 \mathrm{M}$ glycerol, $\left.25^{\circ} \mathrm{C}\right)$ performed by repeating potentiostatic discharging cycles of $10 \mathrm{~s} \mathrm{ON}\left(\mathrm{E}=\mathrm{E}_{\text {appl }}=1.246\right.$ $\mathrm{V}$ vs RHE, no iR-drop correction) and $10 \mathrm{~s}$ OFF $(\mathrm{E}=\mathrm{OCP})$. The corresponding: (c) chromatograms obtained from HPLC analysis (Eluent: $3 \mathrm{mM} \mathrm{H}_{2} \mathrm{SO}_{4}$; injection: $25 \mu \mathrm{L}$; column: BP-OA Benson 2000$0,30 \mathrm{~cm}$, room temperature of $22 \pm 2^{\circ} \mathrm{C}$ ) and (d) Selectivity trend. Post-mortem SEM and EDX (for mapping, scale bar=5 $\mu \mathrm{m}$ ) of the GDE@AgAu electrode after bulk electrolysis for $3 \mathrm{~h}$. 